\title{
Neural Network Application of Risk Identification on Innovative Enterprises in Yunnan Province
}

\author{
Jing Tie* \\ International Business School \\ Yunnan University of Finance and \\ Economics \\ Kunming,China \\ 123278697@qq.com
}

\author{
Wenjing Zhao \\ Statistics and Mathematics School \\ Yunnan University of Finance and \\ Economics \\ Kunming, China
}

\author{
Zhe Niu \\ China Minsheng Bank \\ Kunming, China
}

\begin{abstract}
Innovation enterprise is an important component in the economic system of China, making indelible contribution for the flourishing and prosperity of economy of China. After a long-term development and improvement in many developed countries, the company major risk identification system has formulated a complete system gradually. The establishment method of risk identification system has been gradually transferred to mainly depending on capital market theory and computer information processing quantitative statistics from subjective scoring method and statistical discrimination method.
\end{abstract}

The paper starts from the establishment of risk identification system for innovation enterprise, compares the risk identification methods to the innovation enterprise. The data sample is obtained through financial statement of the enterprise, questionnaire investigation and experts' scoring method. Based on the prediction model of three-tier BP neural network, the risk identification indicators are learned and trained in order to get the importance of all variables and improve and optimize current risk identification evaluation system to the innovation enterprise at last.

Keywords: Innovation enterprise, risk identification, BP neural network component

\section{INTRODUCTION}

First of all, innovative enterprises are the source of the country's economic power. The study is the study of the economy which has a benchmarking effect on the economy of Yunnan Province. At the same time, innovative enterprises want to realize Now the sustainability of innovation ability, its risk identification ability will be an important link. And the neural network method It has a wide range of research space and application significance to identify and predict the major risks of enterprises. The perfection of its model and The final analysis of feedback results will provide favorable conditions for enterprises to identify major risks in the future.

In the risk identification of innovative enterprises, neural networks are used for self-organization, self adaptation and self-learning.

Parameter characteristics, in the enterprise risk identification, based on the input of traditional financial

*Corresponding author indicators, will be enhance the risk prediction ability of innovative enterprises, and provide an important basis for their next development research.

\section{LITERATURE REVIEW}

BP neural network analysis method simulates the neurobiological connection method of brain and carries out data processing. The method is a structural algorithm mode connected mutually by many knots, transferring data to the hidden layer through input layer and then from hidden layer to the output layer. Each knot represents the specific output function, which is called stimulant function and the connection between afterwards knots represents weight.

Liang (2000) points out, McCulloch, a psychologist and Wpitts, a mathematical scientist (1943) set up the neural network mathematical mode, which is called MP model. MP model re-simplifies and re-build the nerve cell of biology according to the mathematical rule and logic, which verifies that the single nerve cell also has the function to implement logic. This is the earliest neural network analysis mode. Minsky (1969) points out the perception is not able to solve the high-order predicate problem in his research published in the early stage, making the research on neural network enter low ebb. Hopfield network model is named after the physicist of California Institute of Technology, USA. His principle is to introduce the concept of "calculation energy", initiating the neural network to connect previous history and simplify the calculation method. BP neural network analysis method needs to set the input variable and target output variable at first. The input data will go through the processing value on the first layer and output value on the second layer, which is forwardpropagating through network. If the output value is not consistent with the expected output, the difference between the two factors and different gradients of error function will be calculated. The network connection weight value and threshold value will be adjusted through error correction weight algorithm until the network output error is smaller than the preset target error value. This stage is the error back propagation stage. The network learning process is over here and the network will be inspected and used after this. 
As a powerful tool to research the complicated financial risk problem, BP neural network analysis method is regarded as an excellent artificial intelligence technology. BP neural network analysis method is an effective tool has been used to evaluate the credit quality since 1990s. In the late of 1970s, the rapid development of computer makes the research on the neural network prosperous. Tam and Kiang (1992) set up BP model of three layers to predict the bankruptcy of the bank. Wilson and Sharda (1992) predict the management failure and enterprise operation failure by referring to the application of neural network. Coats and Fant (1993) make use of BP neural network method to analyze the enterprises in USA and the solvency capacities and profitability capacities of these enterprises in the commercial banks and reach some achievements at last. Altman, Marco and Varetto (1994) make use of BP neural network method to research the financial crisis pre-warning of other foreign companies. West (2000) sets up sample for the enterprises loaning from the commercial bank and divide them into different groups. The first group is named as "good enterprise" that is predicted to be able to or might complete the debt repayment according to previous conditions. The other group is the enterprise with the opposite condition that is not able to or might not complete the debt repayment, which is name as "bad enterprise". According to the sampling classification, five different BP neural network analysis models are established.

The research method on the BP neural network model analysis method starts relatively late in China. At present, the credit pre-warning in the bank and enterprise is still to be completed. Guo and $\mathrm{Li}$ (1995) used to make use of model similar wit the neural network model to predict, analyze and research the possibility of the enterprise to repay the loan to the bank. The research method adopted by Xie (1996) is similar to the neural network method in order to predict the risks. In addition, the research hopes to find out a universally applicable method to help the bank to analyze the financial indicator and carry out credit quality rating through the research conclusion. Wang (1999) makes use of BP neural network analysis technology to evaluate the credit risk of the commercial bank, summarize the advantages and disadvantages of BP neural network analysis method extending to credit evaluation, believing the method to have an extensive development prospect. Yang and Ji (2001) make use of neural network model analysis method of three layers to research the credit quality risk in the financial organizations of China. Pang et al (2003) make use of BP neural network analysis method to divide the enterprise granted credit by some commercial bank in China into three sampling modes, which adds the sample with inter-medium condition between "good enterprise" and "bad enterprise" on the basis of previous two kinds. Such classification improves the original accuracy to $83.34 \%$. Yu proposes feed-forward neural network analysis method based on LM algorithm and the selection of such activation function and configuration order is more conducive to stabilize and improve the prediction function of the model. Yang and In 2002, sampling investigation analysis was carried out to 120 companies. An evaluation mode to these 120 companies was built up based on the operability of current credit quality rating indicator system because of different loan statuses with different models. In addition, the credit scoring critical value of loan decision-making for the bank was calculated. However, this model is based in the premise of the enterprises granted with credit being independent while the influence among all variables is independent mutually, without considering the correlation of all loans. The model belongs to single measurement scope with possible loan repayment crisis. Wang (2005) applies ant colony algorithm into the credit quality evaluation system in the bank for the first time and obtains some achievements. Li and Zhou (2005) propose new model for credit quality research based on BP neural network according to the defects existing in the BP neural network credit quality research based on GA-BP fuzzy neural network. At last, the sampling data is trained and tested by Matlab software and the simulation result shows the prediction error of the built evaluation model is very tiny. Hao (2001) proposes new credit risk evaluation indicator system for the SME from the perspective of supply chain financing. The system combines with the core financial risk of the company as well as conditions of upstream and downstream companies.

BP neural network algorithm is composed by two propagation processes of forward transmission of data and backward transmission leading to errors in the learning process BP neural network model analysis method has been widely applied in various fields due to its advantages, such as information field, automation filed and medical field and so on. $\mathrm{BP}$ neural network analysis has an effective research to the risk identification because of transmission and feedback feature of neural network. Therefore, neural network method is applied greatly in the enterprise risk and credit quality evaluation aspects of the enterprise. According to the features of BP neural network model analysis method, the practicability and applicability in risk identification and asset evaluation field is summarized and concluded.

\section{METHODOLOGY}

BP network analysis method is a typical model of artificial neural network and it is a multiple-layer feed-forward network based on back-propagation (short for BP network). This method has the feature that it is able to approach any continuous function from any accuracy, so usually applied in the prediction model. The principle of BP neural network is to determine the number of input layers by the number of factors influencing the variable. The data sample will be classified into learning \& training sample and prediction inspection sample. The data of training sample will be input each knots in order to complete the transferring between input and output through learning process and training process so that the network system completed training will be obtained. At the time, it enters the prediction inspection stage, the data of the sample can be input correspondingly and obtain the predicted value of the sample to be compared with the true value. The error will be determined and then the problem will be solved. In the network training stage, the network weight training will be carried out according to the given training model in the order of forward propagation - back-propagation - memory traininglearning convergence. In the network prediction stage, the output vector corresponding with the input vector will be obtained in the forward propagation method of the mode according to the trained network weight and given input vector. 
The neural network provides a scientific, improved and simpler method to solve the financial problem. The neural network can be divided into input layer, hidden layer and output layer in the structure. The knot in the input layer is corresponding with the prediction variable while the knot in the output layer is corresponding with the target variable. The transmission functions of BP neural network analysis method include purelin function (linear function), tansig function and logsig function and so on. The accurate transmission functions will be chosen for the knots in the input layer, hidden layer and output layer according to the changes of input financial indicators. The establishment process of the neural network analysis model is a very complicated systematic process and the main crucial steps include follows.

BP neural network includes one input layer, one or several hidden layers and one output layer. Each nerve cell in the hidden layer and output layer is corresponding with an activation function and a threshold value while the nerve cell in each layer is mutually connected with the nerve cell in the adjacent layer through weight. If the threshold value of the nerve cell in the input layer is 0 , the input is equal with the output. Generally speaking, the border judgment can be obtained at random in the networks with two hidden layers in order to realize classification. However, the network with two hidden layers is not better than the network with one hidden layer for the small-scaled network. Above all, the research will adopt BP network structure with three layers.

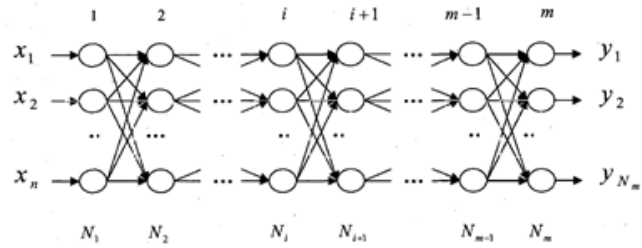

There is no complete theory about the layer number of BP network and knot number of the hidden layer. The network knot number is determined according to the experience and experiment to a large extent. In 1987, the research by HechtNielsen suggested to set the knot number in the hidden layer in the neural network with single hidden layer as $2 \mathrm{~N}+1$ and $\mathrm{N}$ refers to the knot number of the input layer.

According to the normal requirement of nerve cell network, an error limitation between the output result and practical value needs to be set (usually refers to the square error between the output result and practical value). It can set different precision requirement according to the requirement of Matlab software and the model.

\section{Application of BP neural network for innovation enterprises case on Yunnan Province}

If needs to determine how to choose the number of layers in the network and the knots number in each layer at first during establishing the network model.

The dissertation will choose the network structure with single output layer, so the network output value is the comprehensive scoring value of credit quality evaluation rank for the enterprise.
Training Sample Data Table

\begin{tabular}{|c|c|c|c|c|c|c|}
\hline Indicator. & $\begin{array}{l}\text { Return } \\
\text { on Asset. }\end{array}$ & $\begin{array}{c}\text { Inventory } \\
\text { Turnover } \\
\text { Ratio. }\end{array}$ & $\begin{array}{l}\text { Ratio between Current } \\
\text { Assets to Current } \\
\text { Lisbilities. }\end{array}$ & $\begin{array}{l}\text { Industrial } \\
\text { Background, }\end{array}$ & $\begin{array}{l}\text { Credit } \\
\text { Record. }\end{array}$ & $\begin{array}{l}\text { Business } \\
\text { operation } \\
\text { Reputation. }\end{array}$ \\
\hline Enterprise 1. & 0.025 & 0.404 & 50.88 & 0.9 . & 0.9 & 0.8 \\
\hline \begin{tabular}{|l|} 
Enterprise 2.. \\
\end{tabular} & -0.015 & 0.65 & $24,71$. & 0.9. & 0.8 & 0.8. \\
\hline \begin{tabular}{|l|} 
Enterprise 3. \\
.
\end{tabular} & 0.004 & 3.2. & $32.11 . . x$ & 0.5 & 0.9. & 0.5 \\
\hline \begin{tabular}{|l|} 
Enterprise 4. \\
\end{tabular} & 1.99. & 0.37. & 37.94. & 0.6 & 0.9. & 0.6 \\
\hline \begin{tabular}{|l|} 
Enterprise 5. \\
\end{tabular} & 3.99. & 0. & 47.43. & 0.7. & 0.8 & 0.5 \\
\hline $\begin{array}{l}\text { Enterprise } 6 . \\
\text {. }\end{array}$ & 3.13. & 0.1 & 31.23. & 0.6 & 0.6. & 0.5 \\
\hline \begin{tabular}{|l|} 
Enterprise $7 .$. \\
\end{tabular} & -0.012 & 2.39 & 76.12. & 0.5 & 0.7. & 0.6. \\
\hline \begin{tabular}{|l|} 
Enterprise 8. \\
\end{tabular} & 0.155. & 0.35 & 3.21. & $1 .$. & 1. & $1 .$. \\
\hline \begin{tabular}{|l|} 
Enterprise 9.1 \\
\end{tabular} & 3.44. & 0.27. & 32.08 & 0.7. & 0.8 & 0.5 \\
\hline $\begin{array}{l}\text { Enterprise } 10 . \\
\text {. }\end{array}$ & 1.25 & 0.1 & 44.99 & 0.5 & 0.7. & 0.6 \\
\hline \begin{tabular}{|l} 
Enterprise 11. \\
\end{tabular} & 4.07. & 0.38 & 9.32. & 0.5 & 0.6 & 0.5 \\
\hline $\begin{array}{l}\text { Enterprise } 12 . \\
\text {. }\end{array}$ & 1.39 & 0. & 46.46. & 0.5 & 0.7. & 0.7. \\
\hline Enterprise 13. & 2.66 & 0.51. & 4.5. & 0.6 & 0.6 & 0.7. \\
\hline Enterprise 14. & 0.13 & 1.17 & 1.49 & 0.8 & 0.9. & 0.7 \\
\hline Enterprise 15 & 0.15 & 2.25. & 1.45 & 0.7. & 0.8 & 0.8 \\
\hline Enterprise 16. & 4.43. & 1.1. & 27.44. & 0.8 & 0.9. & 0.8 \\
\hline Enterprise 17. & 2.37. & 0.1 & $41.71 .$. & 0.7. & 0.9. & 0.7. \\
\hline Enterprise 18 & 1.96 & 0.58 & 52.96. & 0.6 & 0.4. & 0.5 \\
\hline Enterprise 19. & 2.19 & 0.72. & $27.64 .$. & 0.6. & 0.8 & 0.6 \\
\hline Enterprise 20. & 2.52. & 0.84 & 42.23. & 0.6 & 0.9. & $1 . n$ \\
\hline Enterprise 21. & 3.04. & 0. & 33.68 & 0.6 & 0.7. & 0.6 \\
\hline Enterprise 22 & 3.21. & 0.78 & 33. & 0.8 & 0.9. & 0.9. \\
\hline Enterprise 23. & 2.9. & 0.97. & 43.02. & 0.6 & 0.8 & 0.5 \\
\hline Enterprise 24. & 2.67. & 0.64 & $59.81 .$. & 0.7. & $1 . x$ & 0.7 .1 \\
\hline Enterprise 25. & 10.99 & 0.54 & 20. & 0.7. & 0.8 & 0.7. \\
\hline Enterprise 26. & 2.7. & 0.35 & 23.14 & 0.6 & 0.8 & 0.8 \\
\hline Enterprise 27., & 3.91. & 0.64. & 37.13. & 1.. & 1. & 0.5 \\
\hline Enterprise 28. & 3.82. & 0.44. & 34.43. & 0.7. & 1. & 0.5 \\
\hline
\end{tabular}

Prediction Sample Data Table

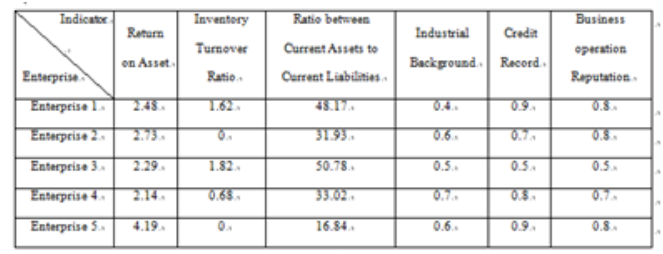

\section{CONCLUSION}

BP neural network model analysis method is able to process data of any type with advantages that many traditional methods cannot compare in the model identification and optimization processing and other fields. At first, BP neural network has low requirement to the sampling data, which can overcome the requirement to model function selection and data symmetry of traditional statistical analysis method, making the analysis process more simple and practical. Secondly, BP neural network has strong adaptive ability, which can find out the inherent rule of the sampling data instead of relying on the rule to get solution through model self-training. This is very positive to weaken the influence of subjective weight confirmation. Thirdly, BP neural network has strong faulttolerant capacity, which can give an effective processing to the uncertainty caused by missing of sampling financial indicator data of the enterprise and non-linear relationship among financial indicators. Even the sampling data is missing in some part, the overall evaluation effect of the model will not be influenced, thereby solving the problem of incomplete information in the credit quality evaluation. Therefore BP neural network model analysis method has strong credit quality evaluation adaptability. 


\section{ACKNOWLEDGMENT}

Thanks the supporting of Yunnan Province Applied basic research project 2016 FD062.

\section{REFERENCES}

[1] AltmanE1.FinaeialRatio,"Diseriminant Analysis and the prediction of Corporate Bankruptcy”,JoumalofFinance, 1968,23

[2] AltmanE1,"Predicting Finaneial Distress of Companies: Revisiting the Z-Score and Zeta Models", working Paper 125, NYUSalomon Center, SePtember1977

[3] Cao, Y.F. (2010), SME Loan Business: Alternative Option of Inclusive Financial Service System, [J], Inner Mongolia: Inner Mongolia Finance Research, 2010,13-14.

[4] Fant, C. "Reeognizing Finaneial Distress Patterns Usinga Neural Network Tool.”, [J]. Finaneial Management, Summer1993; P142-155.

[5] Guo, M.H. (2004), Credit Rating, Beijing: China Renmin University Press, 2004, 45-59.

[6] Huang, H. (2011), Micro Loan Market Starting New Era of Financing for Small and Medium-sized Enterprises, Beijing: Financial Education and Research, 2011, 24-26.

[7] Jensen, HL, "Using neural networks for credit scoring." [J].Managerial Finance(1992)26.

[8] Liang, Q. (2000) Quantization Measurement Research of Credit Risk in Enterprise, Zhejiang: Nankai Economic Research, 2000.6.
[9] Minsky (1969), Complicated Financial Coefficient of Listed Company, [J], Shanghai: Systematic Engineering Theory and Practice, 1969. 43-48.

[10] Peng, K. \& Xiang, Y. (2010), Difficulties to Implement Loan to SME by Banks in China and Countermeasures, Chengdu: Bank Management, 24(6), 18-20.

[11] Sharda (1992), Credit Risk Measurement - New Methods of Risk Valuation and Other Paradigms, Beijing: Machinery Industry Press.

[12] Wang et al. (1999), Commercial Bank Credit Risk Evaluation based on Neural Network Technology, [J]. Systematic Engineering Theory and Practice, 99(9), 24-32.

[13] Wang, B.L. \& Zeng, C.Y. (2005), Credit Financing Problem and Countermeasures in Micro Enterprises, [J]. Hebei: Journal of Hebei Software Institute, 2005, 11-15.

[14] West, D. "Neural network credit scoring models ", [J]. Computer\& Perations research 27(2000). P1131-1152.

[15] Xie, K.J., Modern Enterprise Credit and Enterprise Credit System Construction, Guangzhou: Management World, 2002, 12(11),15-19.

[16] Yang, B.A. \& Ji, H. (2001), Research on Pre-warning to Loan Risk in the Commercial Bank by Making use of BP Network Algorithm, Jiangsu: Systematic Engineering Theory and Practice, 2001, 70-74.

[17] Zhou, K.L. \& Kang, Y.H. (2005), Neural Network Model and MATLAB Simulation Program Designing, Beijing: Tsinghua University Press, 2005, 45-59.

[18] Zmijewski, M.E."Methodological issue srelated to the estimateion off inancial distress Prediction models," [J]. Journal of Aceounting $\begin{array}{llll}\text { Researeh, } & 1984 & \text { (22), supplement:59-82. }\end{array}$ 